\title{
MIDAS
}

Museus e estudos interdisciplinares

$12 \mid 2020$

Varia

\section{A exposição Plasticidade - Uma História dos Plásticos em Portugal: um processo participativo no Museu de Leiria}

The exhibition Plasticity - A History of Plastics in Portugal: A participative process at the Leiria Museum

Maria Elvira Callapez, Raquel Ferreira Coimbra, Sara Marques da Cruz, Vânia Carvalho e Susana França de Sá

\section{OpenEdition}

Journals

Edição electrónica

URL: https://journals.openedition.org/midas/2537

DOI: $10.4000 /$ midas. 2537

ISSN: 2182-9543

Editora:

Alice Semedo, Paulo Simões Rodrigues, Pedro Casaleiro, Raquel Henriques da Silva, Ana Carvalho

Refêrencia eletrónica

Maria Elvira Callapez, Raquel Ferreira Coimbra, Sara Marques da Cruz, Vânia Carvalho e Susana

França de Sá, «A exposição Plasticidade - Uma História dos Plásticos em Portugal: um processo participativo no Museu de Leiria», MIDAS [Online], 12 | 2020, posto online no dia 15 dezembro 2020 consultado no dia 05 março 2022. URL: http://journals.openedition.org/midas/2537 ; DOI: https:// doi.org/10.4000/midas.2537

Este documento foi criado de forma automática no dia 5 março 2022.

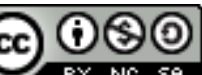

Midas is licensed under a Creative Commons Attribution-NonCommercial-ShareAlike 3.0 International License 


\section{A exposição Plasticidade - Uma História dos Plásticos em Portugal: um processo participativo no Museu de Leiria}

The exhibition Plasticity - A History of Plastics in Portugal: A participative process at the Leiria Museum

Maria Elvira Callapez, Raquel Ferreira Coimbra, Sara Marques da Cruz, Vânia Carvalho e Susana França de Sá

\section{NOTA DO EDITOR}

Artigo recebido a 17.09.2019

Aprovado para publicação a 23.07.2020

\section{Introdução}

1 O projeto de investigação "O Triunfo da Baquelite - Contributos para uma História dos

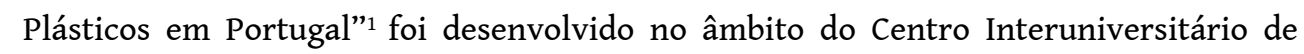
História das Ciência e Tecnologia da Faculdade de Ciências da Universidade de Lisboa (CIUHCT/FCUL), entre 2016 e 2019. A proposta global visava investigar alguns aspetos da história dos plásticos em Portugal, alicerçando-se em estudos técnico-científicos e histórico-sociais, de história da ciência e da tecnologia e de cultura material. Pretendeu-se realçar os aspetos tecnocientíficos dos plásticos; a importância do plástico na evolução do design industrial, na estratégia das empresas e na vida quotidiana; a relação da indústria de plásticos com os seus atores (trabalhadores e elites locais) e com outras indústrias (elétrica e de vidro); e ainda as questões energéticas e ambientais relacionadas com os plásticos. 
2 Os plásticos estão presentes diariamente no quotidiano sob as mais diversas formas e funções. Mesmo quem possui uma imagem negativa dos plásticos e os concebe como sinónimos do artificialismo de uma sociedade, usa-os abundantemente. Em geral, o público não os vê como uma classe especial de materiais, provavelmente porque o plástico está associado apenas a objetos pouco dispendiosos e de fácil acesso. Porém deve muito à investigação científica e tecnológica: é um polímero sintético construído pela mão humana, fruto da investigação aturada de gerações de cientistas.

3 Assim sendo, uma das finalidades deste projeto foi estudar o impacto dos plásticos na sociedade portuguesa, desde a sua chegada em meados de 1930 até à atualidade, através da baquelite, o primeiro verdadeiro plástico, num país fundamentalmente agrícola, sem investigação química e tecnológica nem tradição industrial, em contraste com países industrialmente mais avançados, onde o plástico já se assumia como emblema da modernidade. A investigação centrou-se na região e na cidade de Leiria, no centro de Portugal, por ter sido esta uma região pioneira na indústria transformadora dos plásticos, incluindo, todavia, fábricas de todo o país.

O trabalho incluiu missões de trabalho em fábricas transformadoras de plástico, nacionais, de importância histórica, quer pela precocidade e pelo pioneirismo da sua implantação, quer pela sua dimensão atual. Nestas missões, desenvolvidas essencialmente entre 2016 e 2017, foi possível adotar uma metodologia de pesquisa que visou recolher elementos gráficos, documentais e testemunhos orais dos protagonistas envolvidos neste processo de industrialização. Os entrevistados, antigos e atuais trabalhadores fabris, gerentes e fundadores de algumas fábricas, constituíram uma fonte primária fundamental. Deste trabalho resultaram cerca de 40 entrevistas áudio e dez entrevistas audiovisuais. ${ }^{2}$

5 Entre as várias etapas do projeto incluiu-se a recolha e a catalogação de espólio documental, que consistiu, na sua maioria, em catálogos de fábrica e fotografias e, em menor medida, documentação de carácter contabilístico. ${ }^{3}$ Importa destacar que as fábricas transformadoras de plástico, são, pela sua própria natureza, pouco propensas à valorização do seu passado, uma vez que toda a sua estratégia de viabilidade assenta na antecipação de tendências comercias de futuro. Assim, a maioria das fábricas, nomeadamente as contactadas no âmbito do projeto, não guarda muitos registos materiais escritos de fases anteriores. Além do mais, muita da informação é por natureza sigilosa.

6 A compilação documental e a sua análise permitiu traçar um panorama da história da indústria portuguesa transformadora de plástico, contribuindo para a sedimentação dos estudos na área da história da ciência e da tecnologia. Por outro lado, o espólio reunido - objetos, fotografias, documentos contabilísticos e testemunhos orais tornou-se material organizado em arquivo e passível de gerar mais estudos.

7 Para aprofundar os resultados do projeto "O Triunfo da Baquelite - Contributos para uma História dos Plásticos em Portugal" surgiu a possibilidade da sua comunicação a um público mais alargado, em estreita colaboração com o Museu de Leiria. Desta parceria resultou a exposição Plasticidade - Uma História dos Plásticos em Portugal, patente no Museu de Leiria (tutela do Município de Leiria) entre abril de 2019 e junho de $2021 .{ }^{4}$ Este projeto expositivo reuniu não só o material recolhido durante a investigação como contribuiu para ampliar a ação do Museu de Leiria na valorização da história industrial da região e na relação com as suas comunidades. 
Neste artigo enquadramos o projeto "O Triunfo da Baquelite - Contributos para uma História dos Plásticos em Portugal" e analisamos a exposição Plasticidade - Uma História dos Plásticos em Portugal, nos seus objetivos e abordagens, a criação de uma coleção de plásticos, através de um processo que envolveu as comunidades, e os desafios inerentes à conservação e restauro da coleção.

\section{A importância histórica e social do plástico}

9 A importância histórica e social do plástico e o seu relevo como categoria específica de materiais justifica um breve sumário dos principais marcos da sua história. A indústria dos plásticos nasceu no início do século XX com a baquelite (fig. 1), o primeiro plástico verdadeiramente sintético feito por mãos humanas. Foi sintetizada em 1907, por Leo Hendrik Baekeland, nos EUA, e comercializada em grande escala a partir de 1910. A baquelite rapidamente encontrou inúmeras aplicações, nomeadamente nas indústrias elétrica, de telecomunicações, automóvel, da rádio e utilidades domésticas.

Em Portugal, o fabrico e a comercialização da baquelite teve início em 1936 por parte da Sociedade Industrial de Produtos Eléctricos (SIPE), fundada no Dafundo por João Barbosa Corsino (1895-1963). O seu fundador, empreendedor e professor no Instituto Superior Técnico, é um exemplo paradigmático da necessária aliança entre a investigação e a indústria, o que permitiu algum florescimento industrial.

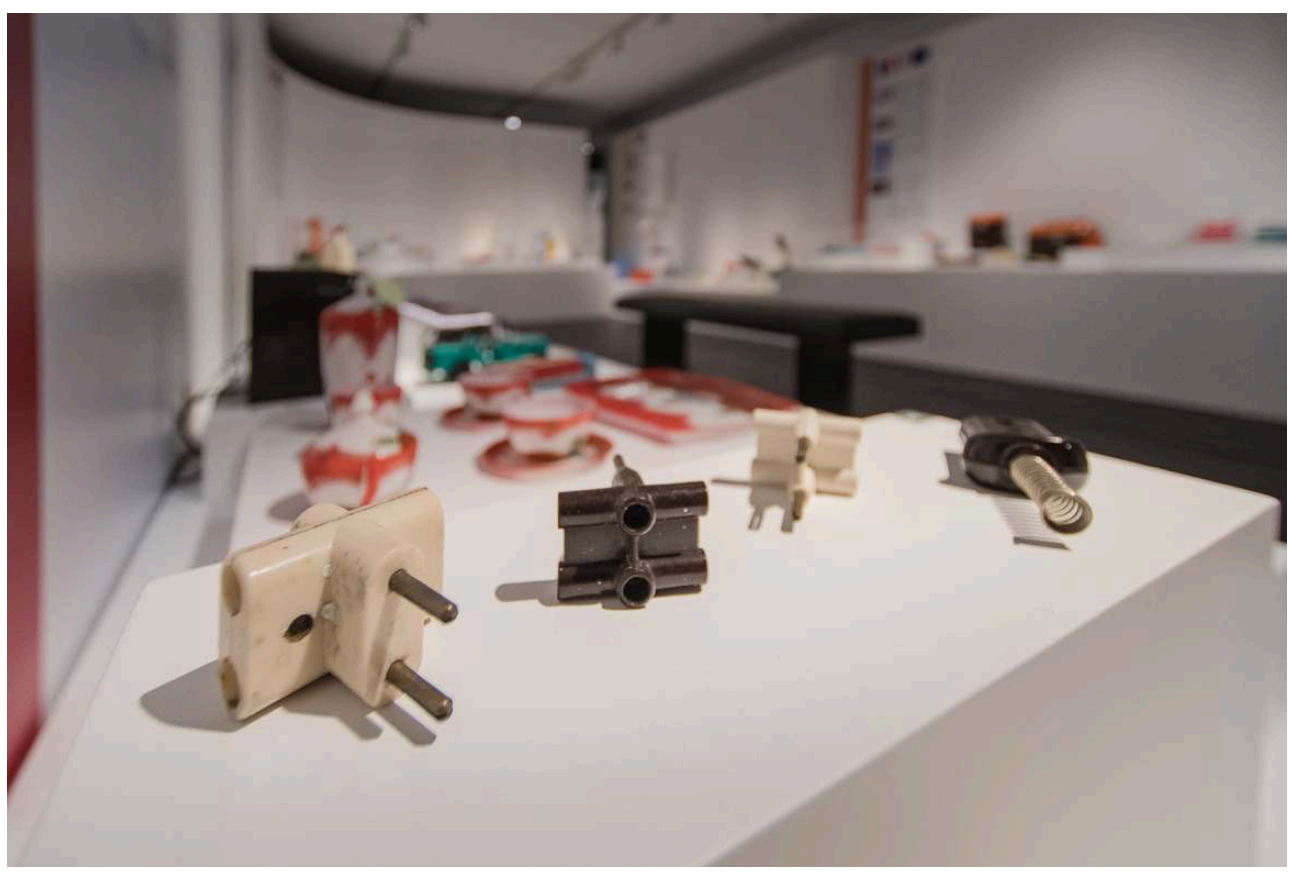

Fig. 1 - Exposição Plasticidade - Uma História dos Plásticos em Portugal. Fichas elétricas em baquelite produzidas pela Sociedade Industrial de Produtos Elétricos (SIPE).

Sérgio Claro (c) Município de Leiria

A década de 1930 ficou marcada pelo desenvolvimento e comercialização de outros tipos de plásticos. Desde o PVC, usado na indústria elétrica, no fabrico de pneus e, mais tarde, na indústria de construção, de embalagens, de automóveis e mobiliário, ao poliestireno, que substituiu o vidro, a madeira e o alumínio em diversas aplicações e era utilizada para fabricar embalagens, produtos domésticos, brinquedos, mobiliário e produtos de tecnologia. Também se desenvolveu o polietileno, usado na indústria 
elétrica, no fabrico de sacos, embalagens, garrafas e recipientes, e que é o plástico que mais contribuiu para a aceitação dos plásticos junto do público, devido à sua utilização em produtos domésticos. 0 polimetacrilato de metilo, comercialmente conhecido como "perspex", tornou-se o primeiro vidro orgânico bem-sucedido, revelando-se um material de guerra essencial e foi maioritariamente usado na indústria aeronáutica. Para além disso, face à escassez de borracha vulcanizada, este acrílico era também utilizado no fabrico de dentaduras postiças (Callapez 2002).

Da II Guerra Mundial surgiu o politetrafluoroetileno, um polímero sintético, conhecido também por "teflon", usado para fins militares durante a Guerra, e depois para utensílios de cozinha devido às suas atraentes propriedades não aderentes. Os anos de 1940 caracterizam-se por um crescimento exponencial da indústria dos plásticos, principalmente depois do final da II Guerra Mundial, período no qual a indústria química sofreu grandes alterações que se fizeram sentir particularmente nas indústrias da química orgânica e dos polímeros sintéticos. A necessidade de combustíveis, nomeadamente de gasolina para os transportes, impulsionou o aumento do consumo mundial do petróleo e, portanto, do aproveitamento dos seus subprodutos. Os plásticos e as borrachas sintéticas tornaram-se comercialmente importantes a nível internacional.

Em 1954 sintetiza-se o polipropileno. A resistência do polipropileno ao calor facilitou a sua difusão no campo dos artigos sanitários, na medida em que é possível a sua esterilização, e no campo dos artigos domésticos (máquinas de lavar louça, exaustores, humidificadores, embalagens). Em 1957, nasceram, quase simultaneamente na Alemanha e nos EUA, os policarbonatos. As principais famílias de plásticos estavam já constituídas (Callapez 2000).

o progresso científico não deixou de se intensificar de forma exponencial nas décadas seguintes e até à atualidade, assistindo-se a uma explosão de novos materiais e combinações, nomeadamente no campo dos compósitos, das matérias biodegradáveis ou dos plásticos de engenharia. ${ }^{5} \mathrm{Na}$ exposição Plasticidade - Uma História dos Plásticos em Portugal estes materiais da contemporaneidade são exibidos como resultado de parcerias estabelecidas com polos tecnológicos portugueses, como se analisará neste artigo.

\section{0 problema dos desperdícios - perceções sobre o plástico}

15 A relevância dos debates em torno do melhor uso a dar aos desperdícios plásticos e o peso do problema ambiental que deriva de um mau uso do plástico, leva à omnipresença dos plásticos nos discursos hodiernos veiculados pela comunicação social, e à sua ubiquidade no discurso mainstream. Podemos debruçar-nos sobre um exemplo relativamente recente como é o número de junho de 2018 da revista National Geographic:

Desde que ajudaram os aliados durante a Segunda Guerra Mundial, os plásticos transformaram as nossas vidas como poucas outras invenções. Facilitaram as viagens espaciais e revolucionaram a medicina. Aligeiram o peso de todos os automóveis e aviões de grande porte, poupando combustível e reduzindo a poluição. Sob a forma de invólucros aderentes, leves como o ar, permitem prolongar o prazo dos alimentos frescos. Através dos airbags, das incubadoras, dos 
capacetes, ou simplesmente ao permitirem a disponibilização de água potável aos pobres nas agora demonizadas garrafas descartáveis, os plásticos salvam vidas todos os dias. (Parker 2008, 18) determinados tipos de plástico. Veja-se o exemplo da mudança no padrão de vendas a retalho, que promoveu o uso de filme de polietileno, já que o saco de plástico se tornou a embalagem quase universal, ou a entrada das mulheres no mercado de trabalho nas democracias ocidentais, que promoveu o uso dos Tupperware no intuito de simplificar a organização doméstica. Assiste-se a uma explosão na utilização dos plásticos que coincide com, alimenta e é alimentada pelo crescimento económico dos anos pós-II Guerra. O plástico ajudou a definir as condições para a veloz expansão do comércio global e do consumismo, que tão cabalmente caracterizam a segunda metade do século XX. Como sublinha Parker:

A revolução acelerou-se no início do século XX, assim que o plástico começou a ser fabricado a partir do mesmo material que nos proporcionava energia abundante e barata: o petróleo. As companhias petrolíferas tinham gases residuais, como o etileno, a sair das chaminés das suas refinarias. Os químicos descobriram que podiam utilizar esses gases como elementos de base, ou monómeros, para construírem polímeros inovadores em vez de aproveitarem apenas os polímeros já existentes. Abria-se assim um mundo de possibilidades. Qualquer objeto podia ser fabricado a partir do plástico e assim aconteceu. (Parker 2008, 18-19)

A fantasia do crescimento económico interminável alimentado pelas políticas extrativistas e pelo consumo em massa dependem hoje do plástico, o substrato do capitalismo avançado (Davis 2015).

A esta inelutável realidade de uma utilização crescente e voraz do plástico não corresponde, no entanto, a uma perceção positiva por parte dos consumidores e da sociedade em geral. A imagem dos plásticos tem sofrido uma grande deterioração, num contraciclo relativo à sua real utilização na economia.

o plástico é também o foco de todas as críticas que o progresso científico suscita, numa espécie de contrapeso ao seu próprio sucesso: «[...] plastic now appears as the archetypal material of invention, mass consumption and ecological contamination (...). More than any other material, plastic has become emblematic of economies of abundance and ecological destruction [...]» (Gabrys, Hawkins e Michael 2013, 2).

20 A necessária reflexão sobre a omnipresença do plástico, assim como o combate aos desperdícios, através da sua reutilização num ciclo de vida eficiente e sustentável foram aspetos introduzidos no contexto da exposição Plasticidade - Uma História dos Plásticos em Portugal, como analisaremos mais à frente no artigo.

\section{O papel de Leiria na história da indústria transformadora de plástico}

21 A indústria transformadora de plásticos nasce em Portugal em complementaridade com a indústria de moldes, atividade esta que se situa a montante dos plásticos e da qual esta depende. Assim, devemos retroceder à implantação da indústria vidreira na região da Marinha Grande (Leiria) cuja origem remonta ao surto empreendedor industrial pombalino do século XVIII. 
22 Essas indústrias vidreiras, que aí singraram, dependiam, para o processo de fabrico dos seus produtos, da técnica de moldagem por sopro: a massa vítrea é colocada num molde, e depois soprada pelo vidreiro de forma a dar à peça a forma do interior do molde. O molde foi sendo fabricado, sucessivamente, em madeira, barro refratário, bronze, ferro fundido e, finalmente, em aço, acarretando sucessivas melhorias ao processo de fabrico, nomeadamente uma semiautomatização do processo, mediante a utilização de uma prensa (Gomes 2015).

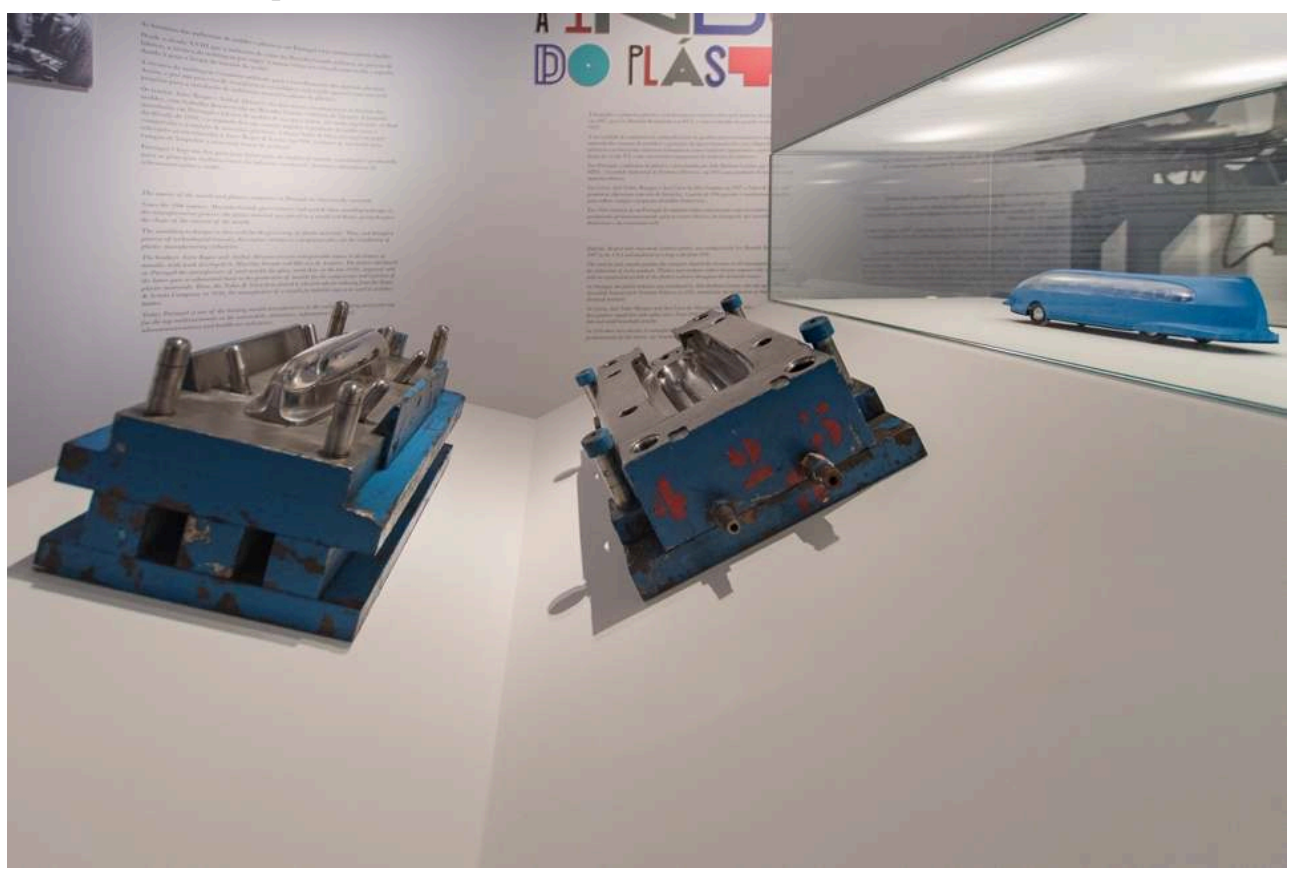

Fig. 2 - Exposição Plasticidade - Uma História dos Plásticos em Portugal. Molde em aço do brinquedo "Autocarro Atómino" (ao fundo), fabricado por Edilásio Carreira da Silva (Marinha Grande), 1961, para a fábrica Plásticos Santo António (Leiria).

Sérgio Claro (c) Município de Leiria 


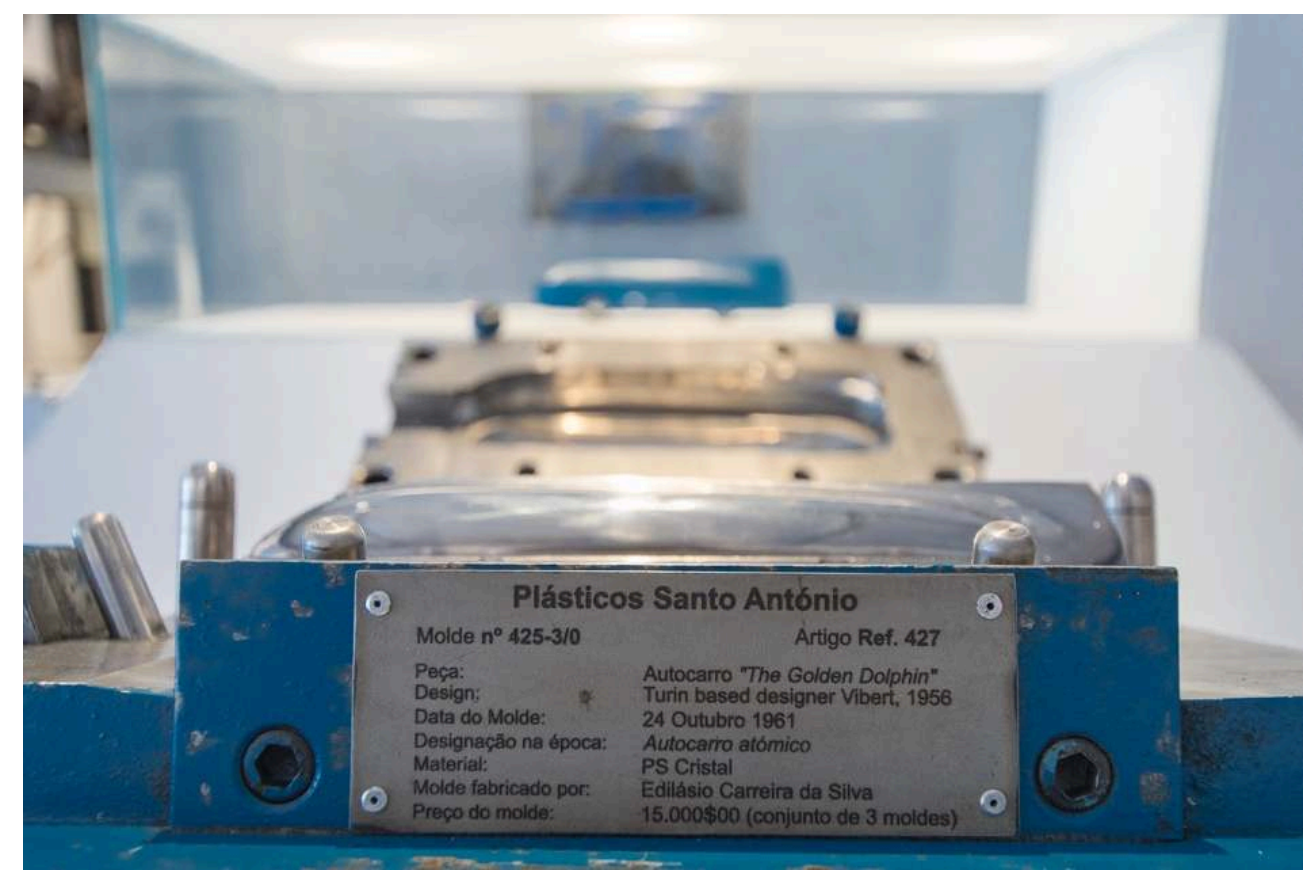

Fig. 3 - Exposição Plasticidade - Uma História dos Plásticos em Portugal. Molde em aço do brinquedo "Autocarro Atómino" (ao fundo), fabricado por Edilásio Carreira da Silva (Marinha Grande), 1961, para a fábrica Plásticos Santo António (Leiria).

Sérgio Claro (c) Município de Leiria

A necessidade de moldes para a indústria de vidro levou à instalação de uma indústria que desse resposta a essa demanda, nascendo, paralelamente ao desenvolvimento da indústria vidreira, a indústria de moldes para vidro na Marinha Grande.

Sabendo que a técnica da moldagem é extrapolável para a transformação das matérias plásticas, facilmente se depreende o resto da equação geográfica: Leiria, ou melhor, o eixo Leiria-Marinha Grande aparece como um local lógico para a instalação de indústrias transformadoras de plástico. A história confirma esta asserção, pela evidência que perdura hodiernamente, do imenso número de indústrias transformadoras de plástico nesta região, algumas das quais remontando aos anos de 1940. Por exemplo, a firma Nobre \& Silva, fundada em Leiria, está intimamente ligada ao nascimento da indústria de moldes para plástico, ao ter solicitado, em 1936, à Aires Roque \& Irmão, o fabrico de um molde de tampas de baquelite para um frasco de perfume (Callapez 2000).

Este percurso histórico evidencia que a região de Leiria está indelevelmente relacionada com a origem da indústria transformadora de plásticos em Portugal, justificando-se a parceria com o Museu de Leiria, através da exposição Plasticidade - Uma História dos Plásticos em Portugal.

\section{A representação de objetos de plástico em coleções museológicas: algumas considerações}

Existem atualmente vários museus que incluem nas suas coleções contemporâneas objetos de plástico, ou com componentes plásticos, essencialmente porque estas matérias foram integradas no mundo da arte e do design como matéria-prima, hoje 
imprescindível, pela imensa variedade de aplicações e possibilidades de trabalho que permite.

No plano europeu, alguns exemplos podem ser destacados, nomeadamente a coleção do Vitra Design Museum, um museu ligado à história do mobiliário e fundado por iniciativa privada, em 1989, em Weil am Rhein, na Alemanha, na dependência da reconhecida empresa italiana Vitra. Uma situação paralela prevalece no Adam Brussels Design Museum que, pese a abundância de objetos/itens com componentes plásticos que incorpora, é um museu de design. Existem também coleções privadas, não constituídas em museu, dedicadas a um determinado material, como por exemplo a Amsterdam Bakelite Colletion, uma coleção sediada em Amsterdão, cujo foco envolve exclusivamente objetos de baquelite.

Outro exemplo de colecionismo é o MoDIP - Museum of Design in Plastics (Reino Unido), que reúne um acervo de objetos de natureza polimérica. Pela sua ligação institucional à Arts University Bournemouth, funciona principalmente como um centro de pesquisa, e os seus objetos não estão em exposição ao público. Não tem uma exposição permanente, mas sim um conjunto de objetos em reserva que podem ser consultados e estudados por especialistas ou investigadores.

Merece especial menção a Fondazione Plart, sediada em Nápoles, que tem como propósito difundir o conhecimento científico e artístico ligado às matérias poliméricas. Este é, porventura, o exemplo que mais se aproxima do que seria um "Museu dos Plásticos".

O projeto de investigação, "Triunfo da Baquelite - Contributos para uma História dos Plásticos em Portugal", desenvolveu relações com algumas destas instituições, nomeadamente através de consultadoria ${ }^{6}$, mas também no âmbito do desenvolvimento da exposição Plasticidade - Uma História dos Plásticos em Portugal, que beneficiou da cedência de imagens e de informação relativa a técnicas de conservação de materiais poliméricos.

31 A valorização dos objetos de plástico como materialização de uma história humana, da ciência e da tecnologia, tem vindo a ser incrementada e potenciada internacionalmente. Cabe mencionar neste âmbito a constituição da Plastics Heritage European Association (PHEA), fundada em 2018, que elenca como um dos seus propósitos fundacionais o estudo de Historic Polimeric Materials - Hipoms, e agrega uma série de instituições académicas e culturais na Europa. A relativa novidade da consideração destes materiais como património cultural pode explicar a ausência de uma coleção pública constituída com este tipo de acervo.

Podem ser referidos para Portugal, no entanto, os museus sobre a história do brinquedo, do design e da arte. Mencionamos o Museu do Brinquedo Português, em Ponte de Lima, cujo acervo é composto, integralmente, por parte da coleção de um colecionador privado, e que inclui um elevado número de brinquedos de plástico material especialmente popular a partir dos anos de 1950, para esta tipologia de objetos. ${ }^{7}$ O MUDE - Museu do Design e da Moda. Coleção Francisco Capelo e o Museu Calouste Gulbenkian - Coleção Moderna possuem também nas suas coleções alguns objetos concebidos por designers e artistas contemporâneos portugueses em materiais poliméricos - para elencar apenas as instituições que cederam objetos para a exposição no Museu de Leiria. 
33 Pese embora a existência de coleções em Portugal que incluem objetos em plástico, evidenciamos a relevância deste projeto, seja do ponto de vista da investigação, seja pelo contributo para a musealização deste tipo de objetos. Com a criação de uma coleção e de uma exposição em Leiria, contribuiu-se para preencher a lacuna de uma coleção dedicada aos plásticos, espelhando uma história dos plásticos nas suas múltiplas vertentes de usabilidade na sociedade.

\section{Uma exposição sobre plásticos no Museu de Leiria: contextos e abordagens}

O Museu de Leiria ${ }^{8}$ acolheu o projeto da exposição Plasticidade - Uma História dos Plásticos em Portugal devido ao papel pioneiro de Leiria na história da indústria transformadora do plástico. Esta história, sendo nacional, é também da região de Leiria, e está interligada com a cultura local, nas suas diversas expressões. Neste sentido, e atendendo à sua vocação regional, o Museu de Leiria é entendido como o "lugar" onde as comunidades encontram a sua identidade, onde se faz o reconhecimento da importância e respeito pelas memórias partilhadas. Nesta perspetiva, o Museu é encarado como espaço de preservação e interpretação da memória e identidade Leirienses. A realização da exposição Plasticidade - Uma História dos Plásticos em Portugal insere-se neste contexto e visa contribuir para a consciencialização das comunidades para a valorizar, enfatizando a história industrial na região, que decorre do imenso número de fábricas transformadoras de plástico, ativas na região desde os anos de 1940 e que são, ainda hoje, um grande esteio económico, demográfico e social da região.

Uma das premissas que modela pragmaticamente a missão do Museu consiste na promoção de uma relação com as comunidades onde se insere. Neste âmbito, subscrevemos as ideias de Ricard Monistrol (Monistrol 2012), quando sublinha a obrigação de um museu de comunicar com as comunidades que o acolhe - sendo um centro de referência e educação. Ou seja, um museu centrado na pessoas, não tanto na organização nem nos objetos, reconhecendo a primazia da participação sobre a sacralização dos objetos. Este paradigma de museologia enaltece ainda conceitos, tais como o de democracia cultural - que postula que todas as culturas presentes numa sociedade devem ter representação; a consciencialização de toda a comunidade no caminho da valorização de uma cultura própria; a existência de um sistema aberto e interativo no qual o museu é uma entidade dinâmica onde o património próprio e dado pela comunidade se inclui em circulação aberta e não linear; a prevalência de diálogo entre sujeitos, com a participação de agentes sociais dentro dos critérios de exposição, como elemento de difusão, discussão e circulação de ideias (Alonso Fernández 2001).

Este enunciado relaciona-se ainda com a função social dos museus. Como destacam Áurea Pinheiro e Cássia Moura:

Nos dias que correm, é inegável a função social que os museus exercem, sobretudo se os entendermos como espaços de sociabilidade, fórum de debates, de troca de saberes, de experiências, de práticas e de afirmação das identidades; como espaços praticados por produtores de cultura e de conhecimentos; como lugares educativos, que se constituem e fortalecem as memórias individuais e coletivas - a memória social; espaços que nos diversos territórios forjam vínculos das pessoas umas com as outras; como lugares de interlocução comunitária, formados por pessoas que pensam a cultura como elemento económico, de sustentabilidade. (Pinheiro e Moura 2016, 48-49) 
37 No contexto da função social dos museus é de realçar o modo colaborativo de funcionamento do Museu de Leiria, na sua ligação à comunidade escolar local e nacional, aos outros espaços museológicos da região, aos voluntários, frequentemente convidados a participar no planeamento e no desenvolvimento das iniciativas do Museu e à comunidade de forma alargada, que consideramos ser simultaneamente construtora, participante e usufrutuária da experiência museológica. ${ }^{9}$ É neste contexto de participação que se enquadrou a exposição e a constituição de uma coleção de plásticos, que pautou pelo envolvimento das comunidades.

38 A exposição Plasticidade - Uma História dos Plásticos em Portugal ocupa a sala de exposições temporárias do Museu de Leiria. Está dividida em vários núcleos, que abordam, sucessivamente, o plástico enquanto material, a indústria dos plásticos e a história dos plásticos através dos objetos finais ${ }^{10} \mathrm{e}$ as potencialidades dos novos plásticos.

39 A proposta de conceção museográfica para esta exposição baseou-se nas características intrínsecas dos objetos de plástico que, em consequência do seu processo de desmoldagem, resultam quase sempre em superfícies e objetos de arestas boleadas, curvas ou de revolução. Nesta premissa assenta a organização do espaço museográfico, composto de uma sucessão de planos retos e curvos, que se "dobram" no sentido do itinerário da visita.

40 A construção da narrativa organizou-se não apenas com o recurso a objetos, mas também através de meios técnicos (imagens e vídeos) de forma a ampliar as possibilidades de apresentação e de interpretação, que no seu conjunto permitiram dar conta da multiplicidade de aspectos que caracteriza este material e esta indústria. Por outro lado, estes meios permitiram também revelar algumas das histórias que estão por detrás dos objetos. Consideramos que a recolha de testemunhos orais e a sua inserção no discurso expositivo é uma forma de dar voz às pessoas, como também uma fonte importante para a documentação dos objetos e respetiva contextualização (ex. modos de fazer, usos) - uma abordagem mais afetiva e biográfica (Semedo, Fontal e Ibanez 2017). ${ }^{11}$

41 Um dos núcleos da exposição abordou a questão premente dos problemas ambientais com o objectivo de evidenciar a omnipresença do plástico sob as mais diversas formas e contrapô-la com a necessidade da sua reintegração num ciclo de vida mais eficiente, sustentável e alargado, pretendendo assim, contribuir para o debate da sua utilização e reutilização. Esta abordagem relaciona-se com os Objetivos das Nações Unidas para o Desenvolvimento Sustentável, reivindicando nesta exposição a importância da «promoção de uma maior consciencialização ambiental, contribuindo, junto dos públicos, como mediadores pedagógicos para o desenvolvimento de comportamentos e atitudes responsáveis» (Camacho 2020, 16). Não se pretendeu condenar a utilização destes materiais, mas incentivar a sua utilização de forma mais consciente e adequada, sensibilizando os públicos.

42 Ainda neste contexto, estabeleceram-se parcerias com o Centro de Interpretação Ambiental de Leiria - que forneceu à exposição conteúdos audiovisuais pedagógicos relacionados com educação ambiental - e com a educadora ambiental Ana Pêgo, que exibiu a mostra Plasticus Maritimus no contexto das mostras rotativas associadas à exposição (abordadas noutro ponto do artigo) e realizou atividades pedagógicas no âmbito da programação associada à exposição. Realçamos, ainda, a instalação do 
Colectivo Til, que refletindo sobre o papel do plástico na sociedade atual, conceberam a obra Mezplasta, que de forma crítica e criativa evoca os diferentes estados desta matéria omnipresente e superabundante (fig. 4 e 5).

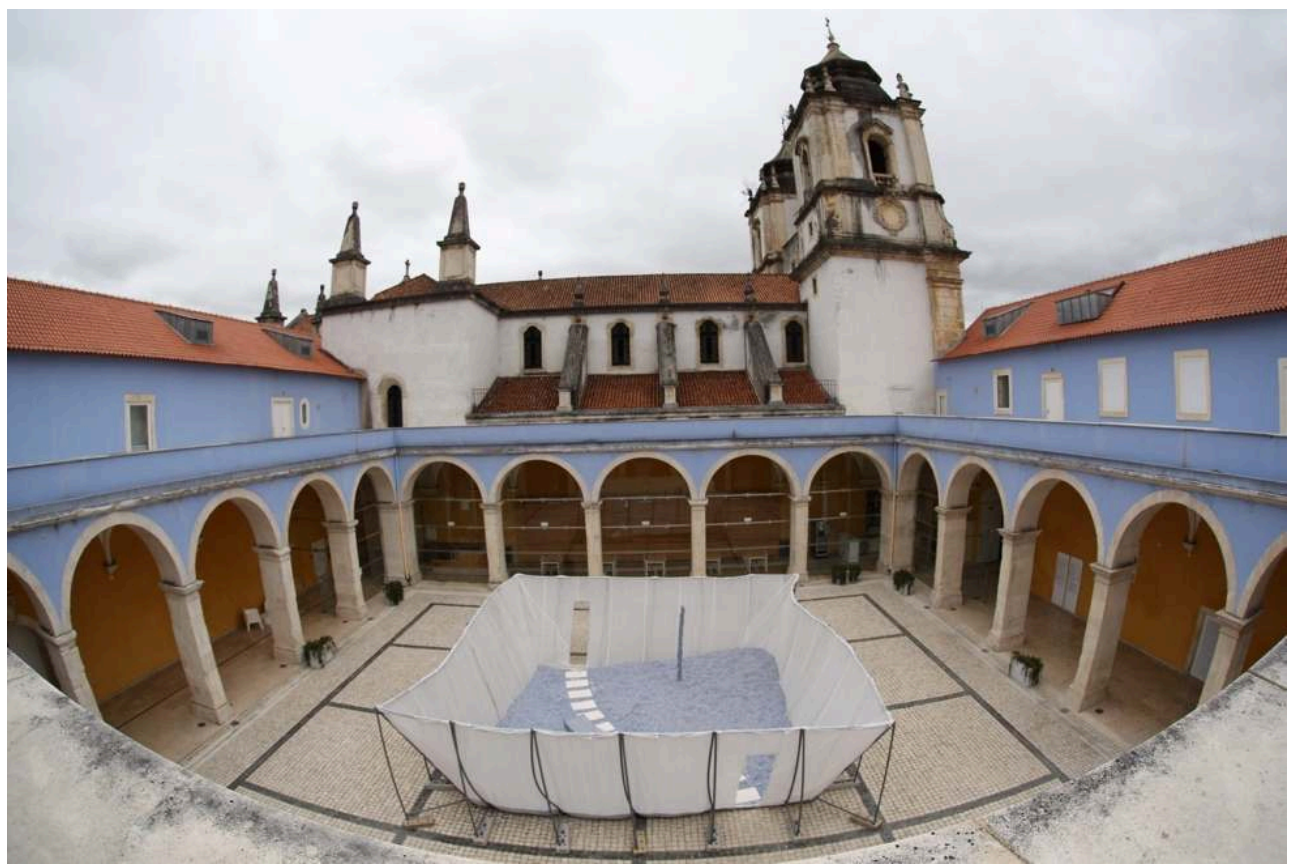

Fig. 4 - Instalação Mezplasta, pelo Colectivo Til, no claustro do Museu de Leiria Fotograf'arte. Município de Leiria

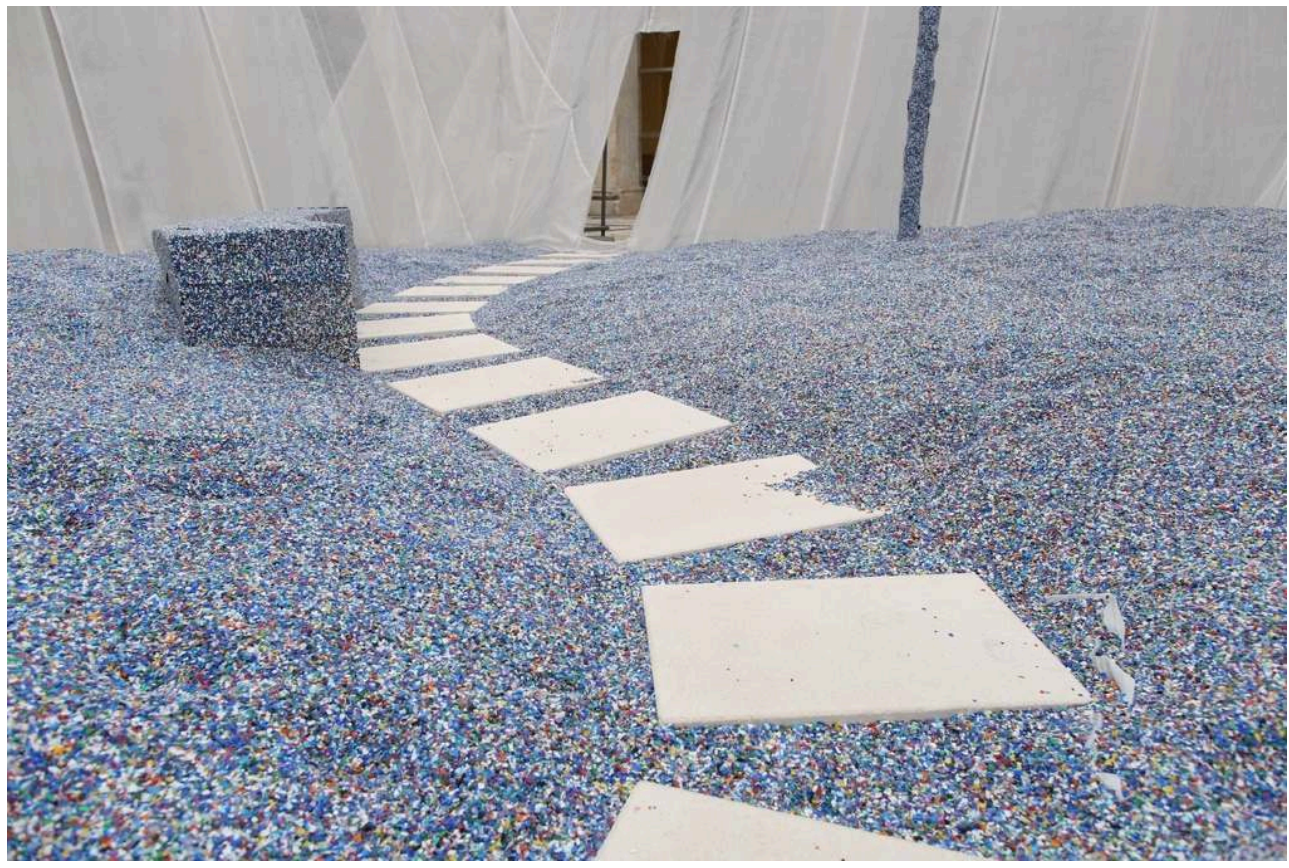

Fig. 5 - Detalhe da instalação Mezplasta, pelo Colectivo Til, no claustro do Museu de Leiria Fotograf'arte @ Município de Leiria

43 Também sobre o tema da omnipresença do plástico foram planeadas nove mostras de curta duração, de naturezas e curadorias diversas, em outros espaços expositivos do Museu no âmbito da programação associada à exposição Plasticidade - Uma História dos Plásticos em Portugal. Esse foi o caso das exposições temporárias: Um Quotidiano de Plástico 
(abril a setembro de 2019) (fig. 6) e Plástico de Brincar (novembro de 2019 a janeiro de 2020) (fig. 7), ambas realizadas na sala do capítulo do Museu de Leiria.

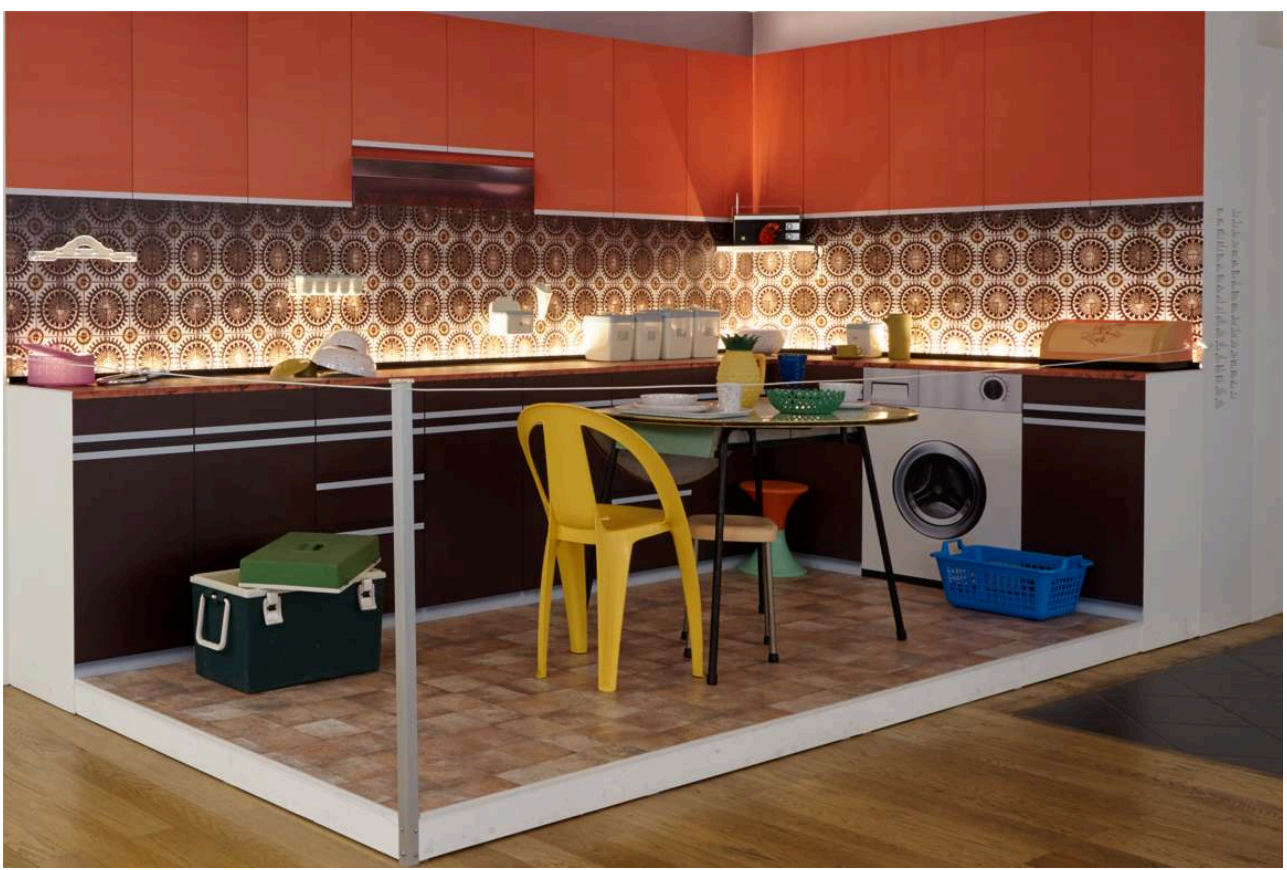

Fig. 6 - Exposição temporária: Um Quotidiano de Plástico (abril a setembro de 2019), na sala do capítulo do Museu de Leiria, no âmbito da programação da exposição Plasticidade - Uma História dos Plásticos em Portugal.

Fotograf'arte @ Município de Leiria

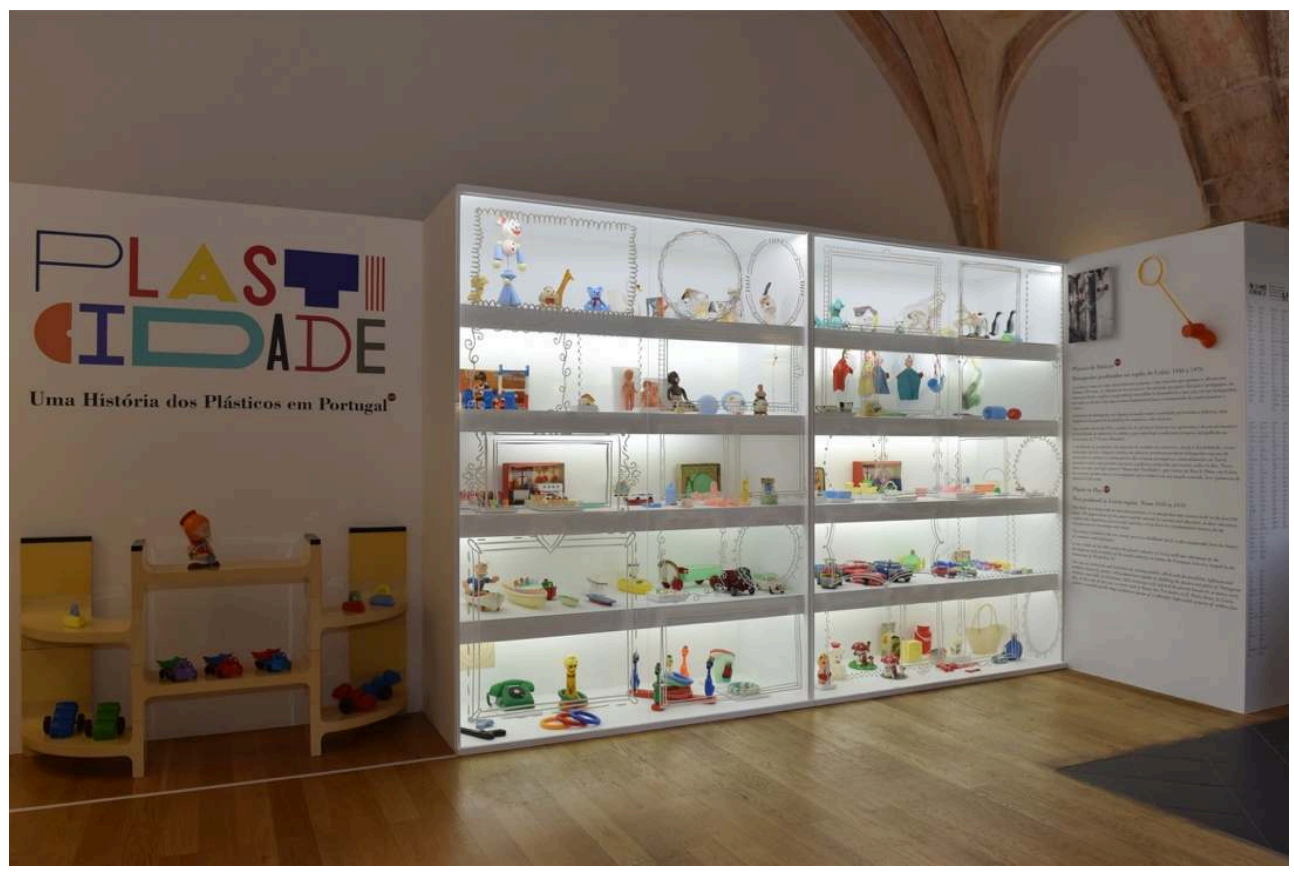

Fig. 7 - Exposição temporária: Plástico de Brincar (brinquedos da região de Leiria fabricados entre 1940 e 1970), na sala do capítulo do Museu de Leiria, patente entre novembro de 2019 e janeiro de 2020, no âmbito da programação da exposição Plasticidade - Uma História dos Plásticos em Portugal. (C) Município de Leiria 
Por fim, realçamos uma outra dimensão abordada na exposição Plasticidade - Uma História dos Plásticos em Portugal, que consistiu na representação do plástico como material de suporte artístico (fig. 8), ocupando o núcleo final da exposição.

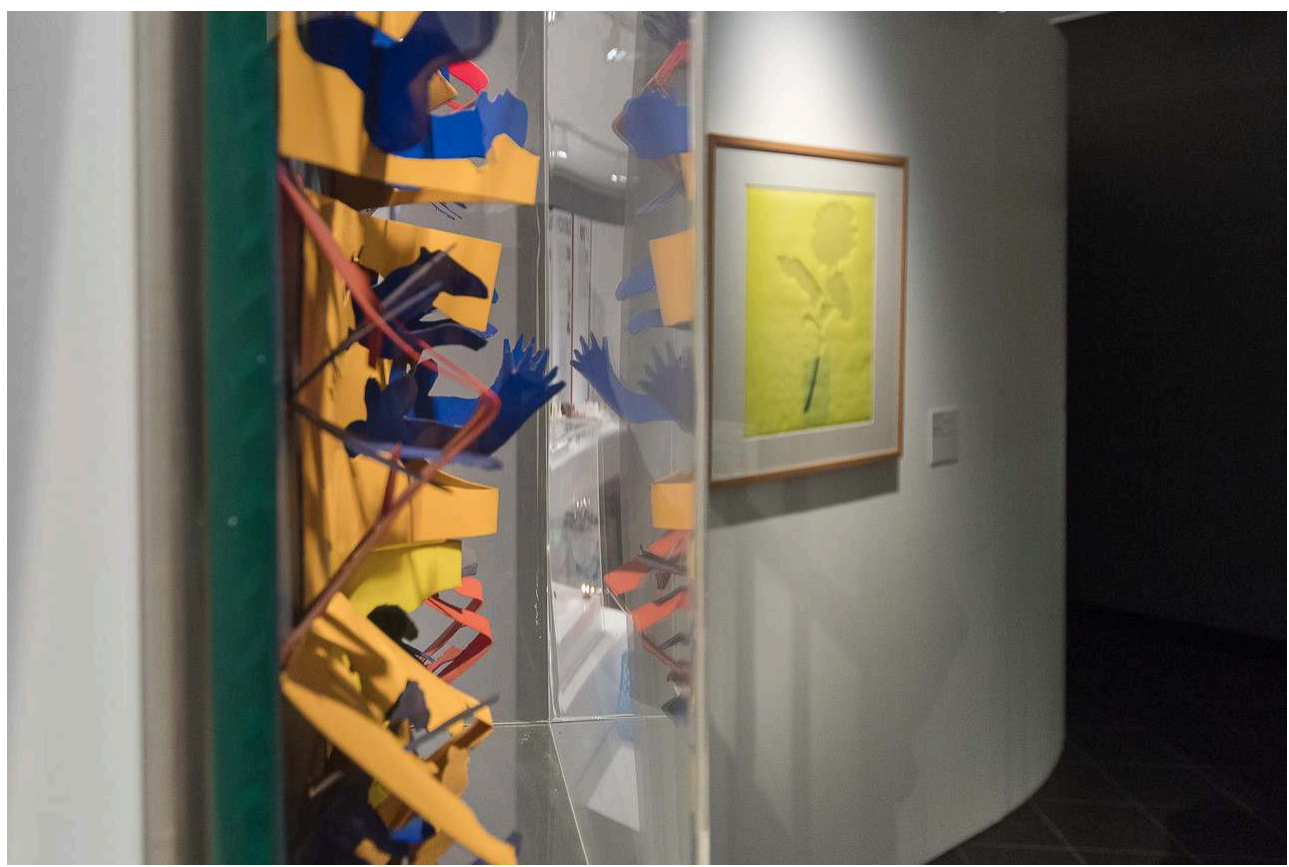

Fig. 8 - O plástico como material de suporte na arte. Em primeiro plano: L'homme Écrase par le Cheval, obra de José Escada, datada de 1967, em acetato de celulose. Ao fundo, Sombra de Dália, de Lourdes Castro, datada de 1970, em Rodhoid, à base de acetato de celulose.

Sérgio Claro (c) Município de Leiria

A exposição e a criação de uma coleção de plásticos justificaram ainda uma intervenção na exposição de longa duração do Museu de Leiria, com o objetivo de estabelecer um diálogo entre objetos produzidos a partir de materiais clássicos (ex. faiança) e objetos de plástico (ex. jarra de plástico em polietileno), justapondo estes materiais distintos (fig. 9). 


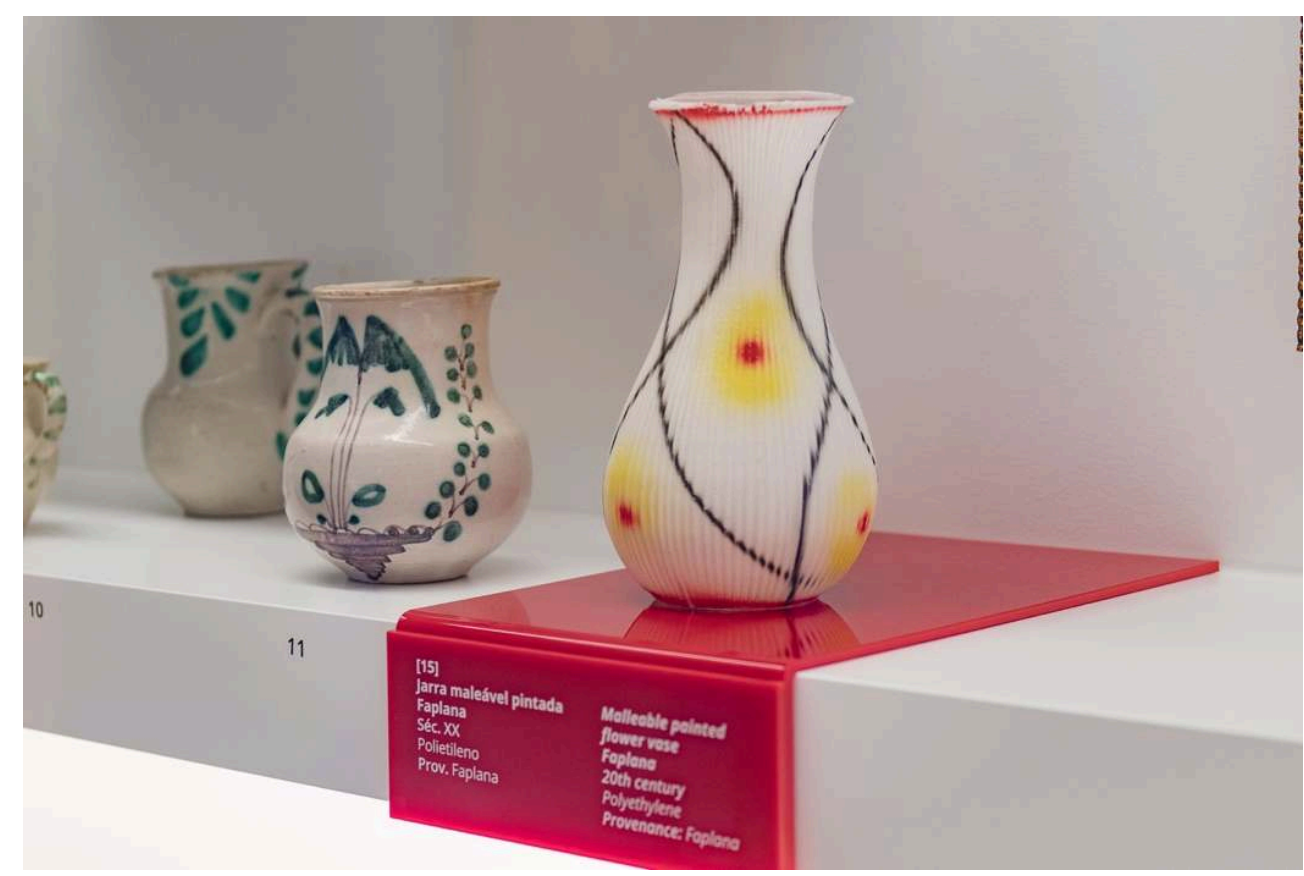

Fig. 9 - Intervenção na exposição de longa duração do Museu de Leiria, potenciando o diálogo entre materiais clássicos, como a faiança do Juncal (Porto de Mós) e o plástico, nomeadamente uma jarra pintada em polietileno.

Sérgio claro () Município de Leiria

\section{A formação de uma coleção de plásticos}

A realização da exposição Plasticidade - Uma História dos Plásticos em Portugal pressupôs reunir acervo que materializasse e representasse, ainda que parcialmente, a história dos plásticos em Portugal e na região de Leiria. As coleções do Museu de Leiria, de carácter multidisciplinar, eram até então constituídas sobretudo por coleções artísticas e arqueológicas de abrangência municipal, mas não albergavam de forma representativa uma coleção de plásticos produzidos na região.

Para este efeito foi desenvolvida uma campanha de recolha de objetos de plástico, coordenada pelo Museu de Leiria, extensível não só às fábricas transformadoras de plástico como também, e principalmente, às comunidades, promovendo o seu envolvimento neste processo. A campanha foi divulgada, entre o último trimestre de 2017 e o primeiro semestre de 2018, junto de meios de comunicação nacionais e locais, nomeadamente através da imprensa escrita tradicional, mas também nas redes sociais, entre outros. ${ }^{12}$

Para a campanha de recolha não foi definido nenhum critério excludente para o tipo de objetos a selecionar, uma vez que o objetivo era que a exposição fosse representativa da globalidade da produção de objetos de plástico em Portugal. Observou-se, pela interação com os emprestadores, que os objetos confiados ao Museu eram aqueles que, por algum motivo, as pessoas consideram mais "dignos" ou mais "nobres".

49 A resposta da comunidade foi quantitativamente elevada, o que permitiu confirmar o impacto dos objetos de plástico, mas também as relações que se estabelecem com os objetos e os sentimentos que despertam. O Museu recebeu mais de 300 objetos de plástico, sendo que cerca de 150 foram finalmente integrados no discurso expositivo. 
Identificaram-se 44 fabricantes distintos, de todo o país, destacando-se neste indicador a região de Leiria (incluindo Marinha Grande) como demonstram os dados apresentados no gráfico n.. 1.

Gráfico $n .^{0} 1$ - Origem geográfica dos fabricantes dos objetos recolhidos na campanha de angariação
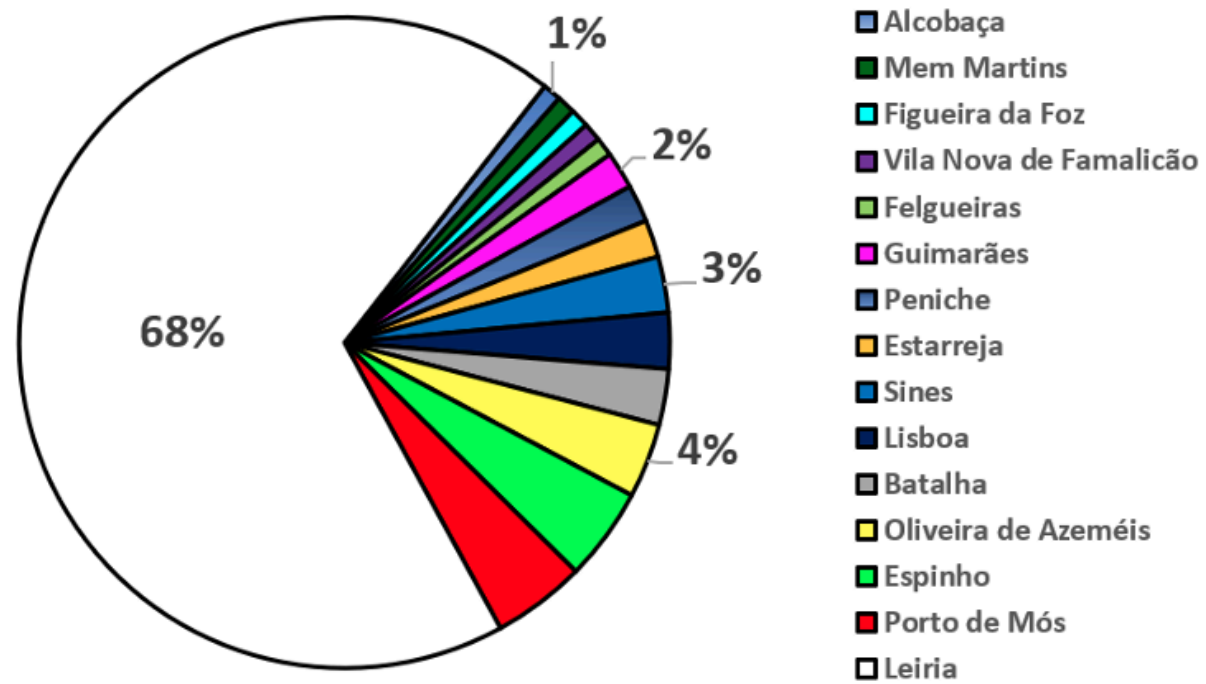

Fonte: Sá et al. (2020) e foram mantidos por distintos motivos, segundo os testemunhos dos emprestadores. Nalguns casos, são objetos ainda estão em uso, independentemente das décadas que tenham, o que indicia a forte durabilidade dos materiais e a sua adequação ao desempenho pretendido, o que são características sempre enaltecidas em relação aos materiais plásticos. Refira-se o caso de um espremedor de citrinos, cuja importância é descrita pelo seu proprietário nos seguintes termos: «Foi oferecido aos meus pais por um vizinho, que trabalhava na empresa Edmar, de Leiria. Segundo ele, era o melhor espremedor de citrinos do mundo! Mas não sei se era o slogan oficial ou propaganda dele». É também o caso de um conjunto de taças e pratos para acampamento, de melamina, que a sua proprietária considerou especialmente belos. Este conjunto teria sido comprado pela sua mãe na década de 1970 para acampamentos de verão em família, e seguramente continuariam a ser utilizadas depois da exposição. Notamos a afetividade e a emoção transferida para os objetos, quase sempre associados a memórias familiares.

A maioria dos objetos evoca uma história associada ao seu proprietário, sendo estes objetos depositários de memórias e vivências remotas, como é o caso de uns binóculos, parcialmente em baquelite, que o pai de um emprestador, capitão num barco pesqueiro, utilizava em alto-mar nos anos de 1950. 

agradáveis, alegres e coloridos, evocadores, através da forma ou cor, de um certo exotismo, como, por exemplo, um jarro em forma de ananás (v. fig. 6), ou um serviço de chá pintado manualmente, com motivos orientais.

$$
\text { produzidos em massa no arranque desta indústria em Portugal (Coelho 2001). }
$$

A recolha de uma série de objetos muito parecidos ou idênticos é também indicador da sua abundância e, portanto, da sua aceitação no quotidiano dos lares portugueses. Vejase o caso das caixas de pão ou dos conjuntos para cozinha de diversas configurações (fig. 10).

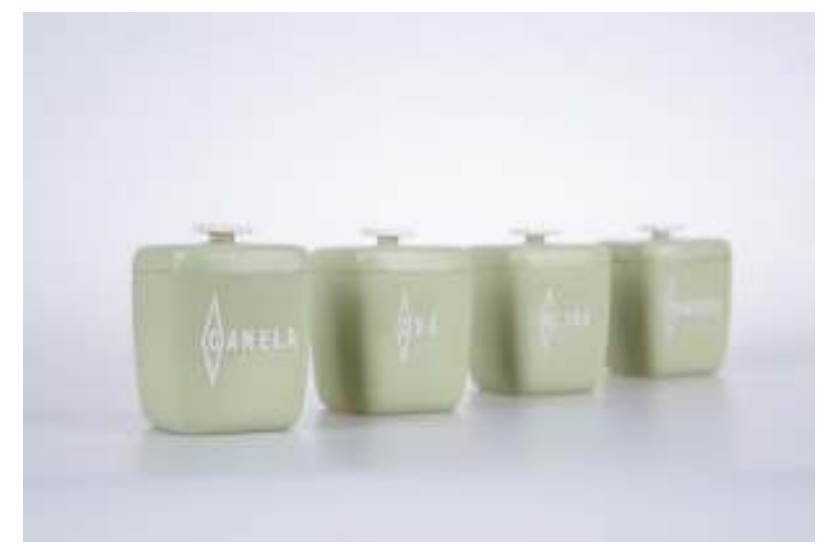

Fig. 10 - Frascos de armazenamento alimentar. Coleção Isabel Florentino Fotograf'arte (c) Município de Leiria

Por fim, note-se a recolha de objetos de uso quotidiano relacionados com processos de substituição. São, a nosso ver, objetos que tiveram aceitação pela exemplar estratégia na conceção do produto. Mantém-se a função (armazenamento de líquidos) e a forma, mesmo que desnecessariamente, como no caso dos característicos "entrançados" de vime, cujo complexo entrançado é reproduzido nos objetos de plástico (fig. 11). Neste contexto levantam-se várias interrogações: porque se terá transposto para a peça em plástico o desenho exato de uma peça em vime, com as consequentes dificuldades, por exemplo, no fabrico de um molde com mais pormenores e de desenho menos óbvio? Terá sido parte de uma estratégia para aumentar a aceitação? Terá sido uma forma de contornar a resistência à mudança? Tornando o reconhecimento do objeto mais fácil, potencia-se apenas a mudança positiva (ex. maior leveza) e, portanto, a aceitação do produto? A manutenção da forma e da função poderia ajudar à aceitação do produto? 


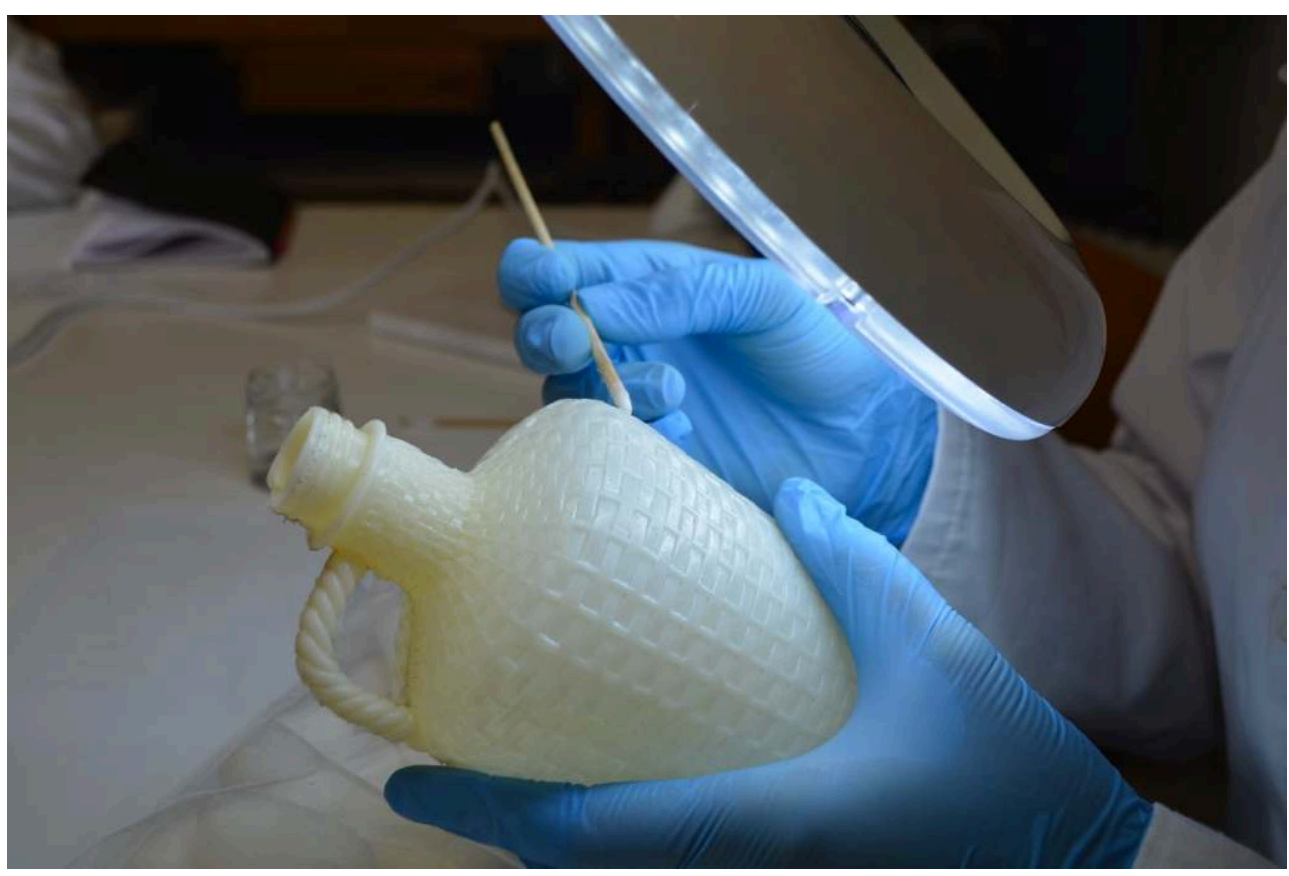

Fig. 11 - Limpeza de objeto em plástico sobre lupa. O formato entrançado da peça reproduz as peças em vime tradicionais.

(c) Susana França de Sá

Para além dos objetos recolhidos houve necessidade de complementar a exposição com uma tipologia de objetos mais diversa, de forma a abranger uma cronologia mais ampla, incluindo uma gama de materiais poliméricos mais representativa da indústria portuguesa. Assim, o conjunto de objetos expostos foi completado através de empréstimos institucionais, que, obedecendo ao discurso museológico em construção, permitiram colmatar as lacunas. Como exemplo, mencionamos as unidades de investigação: o Polo de Inovação em Engenharia de Polímeros (PIEP) da Universidade do Minho) e o Centro de Desenvolvimento Rápido e Sustentado do Produto (CDRSP) do Instituto Politécnico de Leiria, que cederam peças relacionadas, respetivamente, com a investigação aeroespacial e biomédica, fabricadas em plásticos/polímeros desenvolvidos para estes fins (fig. 9). 


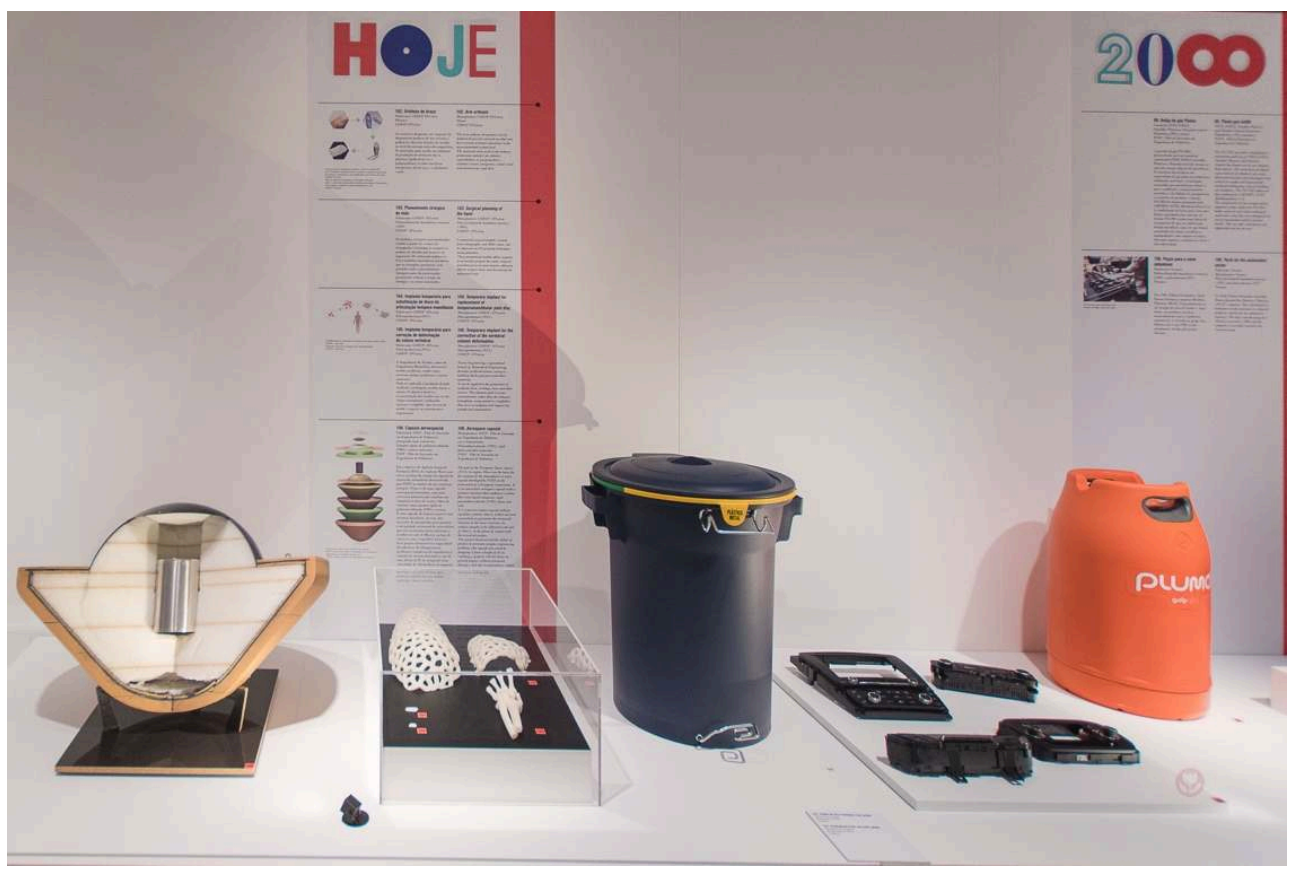

Fig. 9 - Exposição Plasticidade - Uma História dos Plásticos em Portugal. Da esquerda para a direita: cápsula aeroespacial, implantes biomédicos, peças de engenharia automóvel, botija de gás "pluma". Exemplos de peças fabricadas em polímeros, desenvolvidas em centros de investigação nacionais.

Fotograf'arte (c) Município de Leiria foi também possível reunir obras a título de empréstimo, cujo material de suporte é o plástico (acrílico, vinil, poliéster) de artistas contemporâneos portugueses, tais como: Lourdes Castro, José Escada, João Vieira e Nuno Sousa Vieira. Para abordar a relação progressivamente mais densa entre o design de produto e as fábricas leirienses são, por exemplo, elucidativas as peças desenhadas por Eduardo Afonso Dias e por Philippe Starck na década de 1990, fabricadas na fábrica leiriense Faplana.

Globalmente, os objetos foram cedidos por 22 particulares, por 15 empresas concretamente, fábricas que mantêm pequenos "museus" nas suas instalações - e por cinco museus/coleções (MUDE - Museu do Design e da Moda. Coleção Francisco Capelo; Museu do Vidro - Marinha Grande; Museu Dr. Joaquim Manso, Museu Calouste Gulbenkian - Coleção Moderna; e dois colecionadores privados: "A Primorosa Coleção" e Carlos Anjos. Houve ainda a integração na exposição de objetos da coleção do Museu de Leiria e de outros museus da rede concelhia, como sejam o m/ilmo - Museu da Imagem em Movimento e o Agromuseu Municipal $D^{\mathrm{a}}$. Julinha.

A maioria dos objetos recebidos por particulares acabariam por ser doados ao Museu de Leiria de forma definitiva, dando um forte impulso à constituição de uma coleção de objetos poliméricos, que se encontra em desenvolvimento.

\section{A conservação e restauro dos plásticos: uma problemática "nova"}

61 A coleção é constituída maioritariamente por objetos de plástico nunca estudados anteriormente como elementos patrimoniais. A sua manipulação, acondicionamento, 
limpeza, exposição e tratamento levantou várias interrogações à equipa técnica e de investigação envolvida na exposição e a necessidade de empreender parcerias.

Uma equipa do Departamento de Conservação e Restauro da Faculdade de Ciências e Tecnologia da Universidade Nova de Lisboa, parceira do projeto de investigação "O Triunfo da Baquelite", levou a cabo os trabalhos seguidamente sumarizados, quer no laboratório do Museu de Leiria, quer nas instalações do Departamento, em estreita cooperação com o Museu. ${ }^{13}$ Neste âmbito foi possível definir estratégias de preservação, intervenção e exposição, assim como prever as condições de acondicionamento destes objetos em reserva (Sá et al. 2020).

Alguns tipos de plástico, como o policloreto de vinilo plastificado (PVC-P), o nitrato de celulose $(\mathrm{CN})$, o acetato de celulose (CA) e o poliuretano (especialmente na forma de espuma) colocam problemas de conservação, tendo um curto tempo de vida, antes de iniciarem processos de degradação ou deterioração, pondo em risco alguns objetos agora integrados como património cultural. Em geral, a vida útil dos plásticos é curta, principalmente quando comparada com a dos materiais ditos "tradicionais", como a cerâmica ou a pedra. Assim, a compreensão dos problemas de degradação envolvidos e a conservação destes materiais constitui uma das áreas mais ativas das ciências da conservação e restauro no século XXI (Shashoua 2009). Uma vez que o comportamento dos plásticos no decurso do seu envelhecimento ainda não é muito previsível, é fundamental conhecer a composição química de um plástico para definir as estratégias de preservação, intervenção e exibição seguras. Para esse fim, foi utilizada a técnica de espectroscopia no infravermelho (FTIR), recolhendo micro amostras ou realizando análises in situ. Esta análise permitiu identificar o(s) polímero(s) presente(s) nos objetos em plástico e, por vezes, alguns aditivos como plastificantes e modificadores de impacto. Os polímeros mais encontrados nos objetos analisados foram os seguintes: fenol-formaldeído (PF), ureia-formaldeído (UF), melamina-formaldeído (MF), polietileno (PE), polipropileno (PP), poliestireno (PS), poli(cloreto de vinilo) plastificado (PVC-P) e poli(acrilonitrilo-butadieno-estireno) (ABS).

Observando os polímeros detetados nos objetos, que estão datados na maioria dos casos através da informação oral recolhida, confirma-se que não existe um atraso significativo na introdução de materiais na indústria portuguesa em relação às restantes sociedades industriais tidas como mais avançadas. Todos os trabalhadores entrevistados mencionaram que as novidades eram prontamente introduzidas no país, através de redes de agentes comercias muitos ativas e das viagens frequentes por parte dos industriais a feiras da especialidade (Alemanha, Itália). ${ }^{14}$

Uma vez identificados os polímeros por espectroscopia de infravermelho, foi possível estabelecer protocolos de limpeza de acordo com a sua segurança e eficiência em relação a cada um dos polímeros identificados, tais como a aplicação de detergente de pH neutro com pano de microfibra, seguido de um enxague com água destilada; uso de mistura de etanol e água destilada em vez da solução detergente para minimizar o número de fricções e reduzir o risco de abrasão da superfície; ou uso exclusivo de água destilada com panos de microfibra. A espectroscopia de infravermelho contribuiu também para a seleção de solventes e procedimentos seguros e eficientes para a remoção de adesivos ou outros resíduos.

Em relação ao armazenamento, os objetos não expostos foram mantidos em caixas plásticas de polietileno de alta densidade (HDPE) de qualidade alimentar e com folhas de espuma de PE para minimizar o impacto durante o manuseio, armazenadas de 
acordo com os tipos de plásticos, para minimizar as contaminações causadas pela libertação de compostos voláteis (Sá et al. 2020).

\section{Considerações finais}

67 O projeto de investigação "O Triunfo da Baquelite - Contributos para uma História dos Plásticos em Portugal” (2016-2019) permitiu traçar um panorama da história da indústria portuguesa transformadora de plástico, contribuindo para a sedimentação dos estudos na área da história da ciência e tecnologia. Por outro lado, a exposição que nasce deste projeto, Plasticidade - Uma História dos Plásticos em Portugal (2019-2021), realizada no Museu de Leiria, sublinha a pertinência da sua comunicação a um público mais alargado, contribuindo para valorizar a história industrial da região de Leiria. A exposição permite contar essa história, que se revê no esforço empreendedor das pioneiras empresas transformadoras de plástico do eixo Leiria - Marinha Grande. Mas é também uma história dos objetos experienciada, uma vez que grande parte dos objetos foram não só emprestados pela comunidade que os usava, mas também fabricados, nalguns casos, pelas suas próprias mãos. Poderia surpreender a forma como os trabalhadores das fábricas, que em visita à exposição, depositam a mesma carga afetiva nos objetos de plástico, produzidos em série, em ambiente industrial, que seria de esperar de um artesão e os seus objetos únicos, elaborados manualmente. A surpresa esbate-se com a reflexão de que são ambos - objeto em série, objeto manual - fruto de vidas de esforço e de trabalho.

O entusiasmo que os emprestadores demonstraram, ao partilhar as suas histórias e os seus objetos, parece-nos validar o empenho do Museu de Leiria na promoção de uma relação mais próxima e relevante com as suas comunidades. Como sublinha a muséologa Maria Vlachou: «Os museus e as comunidades são uma questão muito pertinente e actual nos museus, porque a nossa [dos museus] sustentabilidade depende muito disso. Até que ponto somos relevantes para a comunidade? Até que ponto eles se ligam a nós? Porque se eles não se ligam a nós é como se não existíssemos» (Vlachou $2013, \mathrm{~s} / \mathrm{p})$. É esse ponto de ligação que o Museu de Leiria procura desenvolver e os resultados refletem estas preocupações, tanto no aprofundamento do conhecimento científico dos objetos de plástico, como na medida da relevância da sua história para a comunidade.

Pese embora a existência de coleções em Portugal que incluem objetos em plástico, evidenciamos a relevância deste projeto, seja do ponto de vista da investigação, seja pelo seu contributo para a musealização deste tipo de objetos e sua preservação. Com a criação de uma coleção e de uma exposição no Museu de Leiria contribuiu-se para preencher a lacuna de uma coleção dedicada aos plásticos, espelhando uma história dos plásticos nas suas múltiplas vertentes de usabilidade na sociedade. 


\section{BIBLIOGRAFIA}

"História e Memórias - Os Construtores de uma Indústria" [documentário]. 2019. [s.l.]: Museu de Leiria e Município de Leiria.

Alonso Fernández, Luis. 2001. Museologia y Museografía. Barcelona: Ediciones del Serbal.

Callapez, Maria Elvira. 2000. Os Plásticos Em Portugal: A Origem da Indústria Transformadora. Lisboa: Estampa.

Camacho, Clara Frayão, coord. 2020. Grupo de Projeto Museus no Futuro: Relatório Final. [s.1.]: Direção-Geral do Património Cultural.

Coelho, José Dias. 2001. Génese e Expansão da Indústria de Plásticos no Concelho de Leiria. Leiria: Câmara Municipal de Leiria.

Davis, Heather. "Life \& Death in the Anthropocene: A Short History of Plastic." 2015. In Art in the Anthropocene: Encounters Among Aesthetics, Politics, Environments and Epistemologies, ed. Heather Davis e Etienne Turpin, 347-358. London: Open Humanities Press.

Gabrys, Jennifer, Gay Hawkins, e Mike Michael. 2013. "Introduction: From Materiality to Plasticity." In Accumulation. The Material Politics of Plastic, 1-14. Oxon: Routledge.

Gomes, Nuno. 2015. Indústria Portuguesa de Moldes para Plásticos - Contributos para a sua História. Tradução Martine Cardoso. Marinha Grande: Bleach Design.

Monistrol, Ricardo. 2012. “Museo y comunidad ¿Un Binomio Imperfecto?” Anuari DifuCom, vol. 1: 1.

Parker, Laura. 2018. “O Plástico.” National Geographic 207: 2-49.

Pinheiro, Áurea, e Cássia Moura. 2016. "Paisagens da Ilha: Património, Museus e Sustentabilidade." In Participação: Partilhando a Responsabilidade, ed. Ana Carvalho, 45-58. Lisboa: Acesso Cultura.

Sá, Susana França de, Sara Marques da Cruz, Maria Elvira Callapez e Vânia Carvalho. 2020. "Plastics that Made History - The Contribution of Conservation Science for the History of the Portuguese Plastics Industry." Conservar Património 35: 85-100.

Santos, Paula Mota. (no prelo). "Histórias e Memórias: Os Construtores de uma Indústria." In Plasticidade - Uma História dos Plásticos em Portugal [catálogo da exposição]. [s.l.]: Município de Leiria.

Semedo, Alice, Olaia Fontal, e Alex Ibanez. 2017. “Objetos e Museus: Biografias, Narrativas e Vínculos Identitários.” MIDAS - Museus e Estudos Interdisciplinares 8.

Shashoua Yvonne. 2009. Conservation of Plastics - Materials Science, Degradation and Preservation. Oxford: Elsevier.

Tomás, Arnaldo. (no prelo). “O Futuro dos Plásticos - Contributo para uma Visão Actual dos Desafios na Utilização dos Plásticos.” In Plasticidade - Uma História dos Plásticos em Portugal [catálogo da exposição]. [s.l.]: Município de Leiria.

Vlachou, Maria. 2013. "Museologia, Entrevista com Maria Vlachou" [entrevista conduzida por Ana Carvalho]. In No Mundo dos Museus, 03-05-2013. https://nomundodosmuseus.hypotheses.org/ 5359 


\section{NOTAS}

1. O projeto foi financiado pela Fundação para a Ciência e Tecnologia (FCT), com o processo PTDC/IVC-HFC/5174/2014.

2. Esta informação está parcialmente recolhida no documentário "História e Memórias - Os Construtores de uma Indústria”, produzido para a exposição Plasticidade - Uma História dos Plásticos em Portugal (2019-2021). Para a análise do percurso laboral destes trabalhadores ver Santos (no prelo).

3. Este espólio documental foi arquivado no Centro de Documentação do Museu de Leiria.

4. O Museu de Leiria recebeu, em 2019, o prémio "The Dibner Award for Excellence in Museum Exhibits", que distinguiu esta exposição. Este prémio, atribuído pela Society for the History of Technology (SHOT), visa reconhecer a excelência em museus e em exposições temporárias que interpretam a história da tecnologia, da indústria e da engenharia para o público em geral.

5. Ver Tomás (no prelo).

6. Neste contexto é de destacar a consultadoria de Alice Hansen, conservadora-restauradora e especialista em materiais contemporâneos na Fondazione Plart; de Arnaud Bozzini, director de exposições no Adam - Brussels Design Museum; e de Susan Mossman, curadora-chefe no Museum of Design in Plastics (MoDIP).

7. Numa análise mais exaustiva poderiam ainda ser mencionados os museus de ciência e tecnologia, de indústria ou ciência e técnica, cujos acervos possuem um grande número de objetos e instrumentos em plásticos.

8. O Museu de Leiria é fruto de uma ideia surgida ainda em tempos da Monarquia Liberal, mas o museu deve a sua concretização aos esforços persistentes de Tito Larcher (1865-1932), que tomaram forma no Decreto de 15 de novembro de 1917, com a criação do Museu Regional de Obras de Arte, Arqueologia e Numismática de Leiria. Em 2006 iniciou-se o processo que devolveu à vivência da cidade o Convento de St.. Agostinho, monumento construído a partir de 1577 (a igreja) e 1579 (o complexo conventual), com a requalificação e adaptação do edifício para as funções de museu. Neste novo contexto, o Museu de Leiria abriu ao público em 2015. O Museu constitui, ainda, o fulcro de uma rede de museus concelhios.

9. O Museu de Leiria foi distinguido, em 2017, com o prémio Siletto no âmbito dos prémios anuais EMYA (European Museum of the Year Award Scheme), atribuído pelo European Museum (EMF), pela capacidade demonstrada em envolver a comunidade que o rodeia, ou seja, por construir um museu participado.

10. Este núcleo, organizado cronologicamente pela data aproximada de fabrico dos objetos, permite perceber a gradual introdução de novos polímeros na indústria portuguesa. Por exemplo, a baquelite, comum nos anos de 1940, vai dando lugar aos polietilenos e poliestirenos, e a partir dos anos de 1970 abundam os objetos em PVC. Estas modificações estão de acordo com a informação recolhida nas entrevistas realizadas.

11. A exposição, bilingue (português e inglês), conta com uma programação associada, incluindo visitas conduzidas pelos distintos membros das entidades envolvidas (ex. artistas, conservadores, industriais, colecionadores), e oficinas pedagógicas, como "Sons em Movimento", uma criação da SAMP - Sociedade Artística Musical dos Pousos | Museu de Leiria, visitas online, em versão breve, visitas orientadas e uma visita virtual 3D.

12. https://www.cm-leiria.pt/pages/617?news_id=2904; https://www.publico.pt/2017/10/12/ p3/noticia/o-museu-de-leiria-quer-os-teus-objectos-antigos-de-plastico-1828773; $\quad$ https:// espalhafactos.com/2017/10/14/museu-leiria-desafia-populacao-recolha-brinquedos-infancia/; https://www.regiaodeleiria.pt/2018/02/leiria-vai-contar-historia-dos-plasticos-portugal/; http://plasticos.ciuhct.org/pt/exposicao/. 
13. Este trabalho foi financiado pelo Laboratório Associado para a Química Verde - LAQV, financiado por fundos nacionais, através da Fundação para a Ciência e a Tecnologia (UIDB/ 50006/2020).

14. Esta informação foi recolhida no documentário "História e Memórias - Os Construtores de uma Indústria", produzido para a exposição e em exibição na mesma.

\section{RESUMOS}

No âmbito do projeto "O Triunfo da Baquelite - Contributos para uma História dos Plásticos em Portugal" (2016-2019) organizou-se a exposição Plasticidade - Uma História dos Plásticos em Portugal (2019-2021) sobre a história dos materiais plásticos, em parceria com o Museu de Leiria. A exposição pretendeu evidenciar a importância dos plásticos, bem como a sua relação com a história da indústria, do design, do consumo e das mentalidades, e da ciência e tecnologia em Portugal, através de um processo de musealização. Neste artigo refletimos sobre a exposição, quanto aos seus objetivos e abordagens, e sobre a formação de uma coleção de plásticos, através de um processo participado com as comunidades. Além disso, a novidade da consideração destes materiais como "objetos de museu" levou também a que fosse analisada a problemática da sua conservação e restauro. Com este artigo destaca-se a relevância deste projeto, seja do ponto de vista da investigação, seja do contributo para a musealização deste tipo de objetos e sua preservação. Com a criação de uma coleção e de uma exposição no Museu de Leiria contribuiu-se para preencher a lacuna de uma coleção dedicada aos plásticos, espelhando uma história dos plásticos nas suas múltiplas vertentes de usabilidade na sociedade.

As part of the project "O Triunfo da Baquelite - Contributos para uma História dos Plásticos em Portugal" (2016-2019), the exhibition Plasticidade - Uma História dos Plásticos em Portugal (2019-2021) was organized on the history of plastic materials, in partnership with the Leiria Museum. The exhibition highlighted the importance of plastics, its relationship with the history of industry, design, consumption and mentalities, and science and technology in Portugal, through a process of musealization. In this article we reflect on the exhibition, its objectives and approaches, and on the formation of a collection of plastics, through a participatory process with the communities. In addition, the novelty in considering these materials as "museum objects" led to the analysis of its conservation and restoration issues. The article emphasises the relevance of this project, whether from the point of view of research, or the contribution to the musealization of these types of objects and its preservation. With the creation of a collection and an exhibition at the Leiria Museum, we contributed to fill the gap with a collection dedicated to plastics, reflecting a history of plastics in its multiple aspects of usability in society.

\section{ÍNDICE}

Keywords: history of plastics, plastics - conservation and restoration, Leiria Museum, exhibition, collecting plastics

Palavras-chave: história dos plásticos, plásticos - conservação e restauro, Museu de Leiria, exposição, coleção de plásticos 


\section{AUTORES}

\section{MARIA ELVIRA CALLAPEZ}

É licenciada em Química Aplicada, mestre e doutorada em História e Filosofia das Ciências pela Faculdade de Ciências e Tecnologia da Universidade de Lisboa. Efetuou o seu pós-doutoramento na Universidade da Califórnia, Berkeley (EUA). É membro integrado do Centro Interuniversitário de História da Ciência e Tecnologia, na Faculdade de Ciências da Universidade de Lisboa. A sua investigação e publicações centram-se na história dos plásticos, na divulgação científica, no ensino das ciências, nos estudos de cultura material, na transferência de tecnologia e na regulamentação ambiental. Tem lecionado em programas de mestrado e doutoramento e tem sido visiting scholar na Universidade da Califórnia. Coordenou o projeto de investigação "O Triunfo da Baquelite - Contributos para uma História dos Plásticos em Portugal” (2016-2019). Centro Interuniversitário de História das Ciências e da Tecnologia, Faculdade de Ciências, Universidade de Lisboa, 1749-016 Lisboa, Portugal, mariaelviracallapez@gmail.com

\section{RAQUEL FERREIRA COIMBRA}

Mestre em Museologia e Museografia pela Faculdade de Belas Artes da Universidade de Lisboa (2008). Licenciada em Pintura pela Escola Universitária das Artes de Coimbra (2002) e fez o curso Introduction to Curating pela Central Saint Martins College of Art \& Design (Londres, 2003). Tem experiência de trabalho em instituições de âmbito cultural e patrimonial nas áreas da programação museológica, discurso expositivo, estudo e inventariação, e mediação cultural. Foi coordenadora técnica e a museóloga responsável pelos projetos: “Centro de Diálogo Intercultural de Leiria" (2017), no âmbito da Rede Portuguesa de Judiarias; “Museu do Azeite”, Bobadela, Oliveira do Hospital (2018); “Centro interpretativo do Cabeço da Mina”, Vila Flor (2018). É museóloga e curadora da exposição Plasticidade - Uma História dos Plásticos em Portugal. Trabalhadora independente, Portugal, raquel.coimbra@gmail.com

\section{SARA MARQUES DA CRUZ}

É licenciada em História, ramo científico, pela Faculdade de Ciências Sociais e Humanas da Universidade Nova de Lisboa. Desde 2015 colabora com o Museu de Leiria nas áreas de pesquisa e produção de conteúdos para exposições, inventário e serviços educativos. Entre 2017 e 2019 foi bolseira de investigação no projeto "O Triunfo da Baquelite - Contribuições para uma História dos Plásticos em Portugal".

Centro Interuniversitário de História das Ciências e da Tecnologia, Faculdade de Ciências, Universidade de Lisboa, 1749-016 Lisboa, Portugal, saramarquesdacruz1@gmail.com

\section{VÂNIA CARVALHO}

É mestre em Evolução e Biologia Humanas e licenciada em História, variante Arqueologia. Integra, desde 2006, a equipa do município de Leiria, atualmente na Divisão de Ação Cultural, Museus e Turismo. Coordena o Centro de Diálogo Intercultural de Leiria (CDIL), o Centro de Interpretação do Abrigo do Lagar Velho, no vale do Lapedo e o Museu de Leiria, incluindo a Reserva Arqueológica Municipal. É responsável pelos projetos de investigação arqueológica (Plano Nacional de Trabalhos Arqueológicos) do Castelo de Leiria (2009-2012) e da Carta Arqueológica concelhia e codiretora do projeto “Ocupação Humana plistocénica nos Ecótonos do Rio Lis" (EcoPLis). Faz acompanhamento de processos de obras no concelho para aconselhamento e parecer técnico sobre medidas de minimização arqueológica e patrimonial. Museu de Leiria, Câmara Municipal de Leiria, Largo da República, 2414-006 Leiria, Portugal, vcarvalho@cm-leiria.pt 


\section{SUSANA FRANÇA DE SÁ}

É doutorada em Conservação e Restauro do Património Cultural pela Faculdade de Ciências e Tecnologia da Universidade Nova de Lisboa (2017). O foco da sua investigação é estabelecer estratégias de conservação e restauro para suprir necessidades urgentes em coleções de museus contendo materiais problemáticos como os plásticos, espumas e borrachas. Desde 2011, integrou seis projetos de investigação focados na preservação e na história dos plásticos, bem como no desenvolvimento de soluções sustentáveis para a sua conservação. É desde 2018 professora auxiliar convidada no Departamento de Conservação e Restauro da Faculdade de Ciências e Tecnologia da Universidade Nova de Lisboa.

Departamento de Conservação e Restauro, Faculdade de Ciências e Tecnologia da Universidade Nova de Lisboa, 2829-516 Monte da Caparica, Portugal, susana.sa@fct.unl.pt 